\title{
Antitumor effect of the paclitaxel-eluting membrane in a mouse model
}

\author{
JIN-SEOK PARK ${ }^{1}$, SEOK JEONG $^{1}$, DON HAENG LEE ${ }^{1}$, JIN HEE MAENG $^{2}$, IN SUH PARK ${ }^{3}$ and SANGSOO PARK $^{4}$ \\ ${ }^{1}$ Department of Internal Medicine, Inha University School of Medicine, Incheon 400-711; \\ ${ }^{2}$ Utah-Inha DDS and Advanced Therapeutics Research Center, Incheon 461-713; ${ }^{3}$ Department of Pathology, \\ Inha University School of Medicine, Incheon 400-711; ${ }^{4}$ Department of Biomedical Engineering, \\ Eulji University, Seongnam, Gyeonggi 461-713, Republic of Korea
}

Received August 11, 2016; Accepted September 1, 2017

DOI: $10.3892 / \mathrm{ol} .2018 .9164$

\begin{abstract}
Local treatment of primary bile duct cancer, which grows locally at the primary lesion and seldom metastasizes to distant sites, is challenging. The present study evaluated the antitumor effect, systemic toxicity, biodistribution and survival benefit of the paclitaxel-eluting polyurethane membrane in a tumor model. Membranes containing various amounts of paclitaxel $(0,100,300,600$ and 1,200 $\mu \mathrm{g} / \mathrm{disc})$ were inserted beneath the tumor mass in mouse models. Tumor size and body weight of the tumor models were monitored for 26 days after insertion of the membrane. The terminal deoxynucleotidyl transferase-mediated dUTP nick end labeling assay was performed in the tumor tissues. High-performance liquid chromatography was performed for evaluation of paclitaxel concentration in peripheral tissues. Tumor volumes on day 26 of membrane treatment were decreased in a dose-dependent manner. No significant difference in body weight was observed in the groups. A greater number of apoptotic cells were counted per high power field in tumor tissues following an increase of paclitaxel concentration. In the 1,200 $\mu$ g-group, concentrations of paclitaxel were significantly higher in tumors compared with those of other tissues and serum. The paclitaxel-eluting membrane demonstrated a significant and dose-dependent antitumor activity, and did not exert systemic toxicity in the tumor model.
\end{abstract}

\footnotetext{
Correspondence to: Professor Seok Jeong or Professor Don Haeng Lee, Department of Internal Medicine, Inha University School of Medicine, 7-206, 3-Ga, Sinheung-dong, Jung, Incheon 400-711, Republic of Korea

E-mail: inos@inha.ac.kr

E-mail:1dh@inha.ac.kr
}

Abbreviations: PTX, paclitaxel; PU/DMAc, polyetherurethane in a dimethylacetamide; TUNEL, terminal deoxynucleotidyltransferase-mediated dUTP nick end labeling; HPLC, high-performance liquid chromatography

Key words: paclitaxel, membrane, drug delivery system, bile duct neoplasm

\section{Introduction}

Primary bile duct cancer usually exhibits biological behavior; its growth is local, at the primary lesion, seldom metastasizing to distant sites, and it requires other local therapy at the surgically unresectable stage. Numerous previous studies of local application using drugs for primary treatment of bile duct cancer have been performed (1-7).

Drug delivery systems that release certain drugs into specific sites in the body at a controlled rate include microspheres, colloids, bioadhesives, micelles, intratumoral injections, films, liposomes, peptide conjugates, lipid nanoparticles, microemulsions, nanospheres, pastes and drug-eluting stents.

Paclitaxel (PTX) is a microtubule inhibitor that has been used in the treatment of various types of cancer, including breast cancer, ovarian cancer and non-small cell lung cancer (8). PTX exhibits dose-dependent cytotoxicity, as well as antimetastatic and antiangiogenic activities $(9,10)$. PTX has pharmacokinetic properties, which demonstrate a steep dose response for therapeutic effects and toxicity, and is more adequate for localized delivery compared with systemic delivery (11). Therefore, a delivery system loaded with PTX at the tumor site may allow for a high local concentration of the drug that is detrimental to cancer cells, preventing re-growth and metastasis of the tumor (12).

PTX-eluting stents have been used for the prevention of in-stent re-stenosis in coronary artery disease, however, a previous in vitro study reported the efficacy of PTX-eluting stent in malignant extrahepatic cholangiocarcinoma and serves as the basis for development of a drug-eluting stent for malignant biliary stricture (2). After then, many tries are ongoing to develop PTX-eluting stent for the treatment of malignant biliary stricture. In vitro and in vivo animal studies have been performed to assess tissue compatibility, and drug-releasing profiles of PTX-eluting metal stents $(5,6)$. In addition, a human trial for PTX-eluting stent in malignant biliary obstruction was conducted. In this study, the PTX-eluting stent demonstrated promising results for prolonging the duration of stent patency (mean 429 days) and patient survival (mean 350 days) (7). To the best of our knowledge, there have been no reports of antitumor activity of PTX-eluting membranes as a stent-covering material in an animal model. 
Previously, we developed a PTX-eluting membrane as a covering material for drug-eluting stents for local control of bile duct cancer and evaluated the release behavior of PTX in an in vitro study of the membrane (13). In the previous study (13), the PTX-releasing profile demonstrated that PTX was released slowly and steadily from polyurethane membranes containing different weight percentages of PTX over 4 weeks following the initial fast-release phase in the first 4 days.

The present study evaluated the antitumor effect and systemic toxicity of local and controlled-releasing membranes for various amounts of PTX in a tumor model, and compared the degree of apoptosis in the tumor according to the amount of PTX in the membrane. The present study also assessed the biodistribution of PTX in the tumor model in order to identify the local effects of this releasing system.

\section{Materials and methods}

Preparation of the PTX-containing membrane. The PTX-eluting membrane (S\&G Biotech Inc., Seongnam, Korea) was prepared for in vivo animal study. PTX was purchased from Samyang Genex Co., Ltd. (Daejeon, Korea) and commercial polyurethane, Pellethane ${ }^{\mathrm{TM}}$ 2363-80 AE was purchased from The Dow Chemical Company (Midland, MI, USA). Film casting solutions were made by dissolving the PTX with premixed polyetherurethane in a dimethylacetamide (PU/DMAc) solution. PT was dissolved at $0.5,1.5,3$, and $6 \mathrm{mg} / \mathrm{ml}$ in order to make concentrations of 100 , 300,600 , and 1,200 $\mu \mathrm{g} / \mathrm{disc}$, respectively. Subsequently, $200 \mu \mathrm{l}$ PTX/PU/DMAc solutions were pipetted onto $1.5 \mathrm{~cm}$ diameter Teflon ${ }^{\circledR}$ wells (O\&G, Hwaseong, Korea). The plate was stored inside an oven at $50^{\circ} \mathrm{C}$ for $24 \mathrm{~h}$ to evaporate the solvent, and then inside a vacuum oven at $70^{\circ} \mathrm{C}$ for an additional $24 \mathrm{~h}$ for complete removal of the solvent. The films were removed from the Teflon ${ }^{\circledR}$ plate and weighed.

The membrane was disc-shaped with a $15 \mathrm{~mm}$-diameter, $176.6 \mathrm{~mm}^{2}$-area and $120 \mu \mathrm{m}$-thickness. The membrane, which contained various amounts of $\operatorname{PTX}(0,100,300,600$ and $1,200 \mu \mathrm{g} / \mathrm{disc})$ was polyurethane-based, and designed for local and controlled release of PTX. Therefore, the amounts of PTX per unit area of the membrane were $0,56.5,169.5$, 339.0 and $678.0 \mu \mathrm{g} / \mathrm{cm}^{2}$ in $0,100,300,600$ and 1,200 $\mu \mathrm{g} / \mathrm{disc}$, respectively.

Cell culture. CT26 murine colon adenocarcinoma cells were commercially obtained from the Korean Cell Line Bank (Seoul, Korea). The cell line was grown in Dulbecco's modified Eagle's medium (Invitrogen; Thermo Fisher Scientific, Inc., Waltham, MA, USA) supplemented with $10 \%$ fetal bovine serum (Welgen Inc., Worcester, MA, USA) and $1 \%$ penicillin-streptomycin. Cells were maintained under an atmosphere of $5 \% \mathrm{CO}_{2}$ at $37^{\circ} \mathrm{C}$ in a humidified incubator.

Animal model. Female Balb/c mice (aged 6 weeks, mean weight $20 \pm 2 \mathrm{~g}$ ) were purchased from Orient Bio Inc. (Seongnam, Korea). The animals were kept in specific pathogen-free animal facilities with controlled temperature and humidity under conventional conditions at a temperature of $22 \pm 2^{\circ} \mathrm{C}$, a relative humidity of $55 \pm 10 \%$, and a $12 \mathrm{~h}$-dark/light illumination cycle. They were fed standard diet chow pellets and water ad libitum.
All procedures performed with the mice were approved by the Animal Care and Use Committee of the Inha University School of Medicine (Incheon, Korea), according to the institutional policies. Ethical approval for the experiments with mice were obtained from the Ethics Committee of Inha University School of Medicine (approval no. INHA 130816-226).

CT26 cell suspension containing $1 \times 10^{6}$ cells in a volume of $100 \mu 1$ Dulbecco's Modified Eagle Medium was injected subcutaneously into the backs of all animals. When tumors reached a volume between 100 and $250 \mathrm{~mm}^{3}$, a total of 50 mice were randomly allocated into five groups for assessment of antitumor activity of the PTX-eluting membrane; 0 , $100,300,600$ and 1,200 $\mu \mathrm{g}$ PTX/disc of the membrane.

Antitumor activity and toxicity of the PTX-eluting membrane. Membranes containing various amounts of PTX $(0,100$, 300,600 and 1,200 $\mu \mathrm{g} /$ disc) were inserted into the subcutaneous layer beneath the tumor mass of CT26 tumor-bearing mice 7 days after cell inoculation. Using a caliper, tumor size was determined repeatedly and the body weight of the tumor model was monitored until 26 days after insertion of the membrane. Tumor volume was evaluated according to the method suggested by Uchiyama-Kokubu and Watanabe (14). Euthanasia was performed with $\mathrm{CO}_{2}$ inhalation at 26 days after membrane insertion and the tumor masses were harvested.

Terminal deoxynucleotidyl-transferase-mediated dUTP nick end labeling (TUNEL) assay. The TUNEL assay was performed using the ApopTag ${ }^{\circledR}$ Peroxidase In Situ Apoptosis Detection kit (S7100; EMD Millipore, Billerica, MA, USA), according to the manufacturer's protocol, following deparaffinization of $3-\mu \mathrm{m}$ thick tumor tissue sections for in situ detection of apoptotic cells in the extracted tumor tissues. Hematoxylin $\left(75 \mu \mathrm{l} / 5 \mathrm{~cm}^{2}\right)$ was used for counterstaining $5 \mathrm{~min}$ at room temperature.

Following TUNEL staining, brown-colored cells were considered as apoptotic cells. To compare the degree of apoptosis, the present study counted and summated the cells using five high power fields (magnification, x400) of light microscopic examination, and calculated the mean values.

\section{Biodistribution of PTX following treatment of the PTX-eluting} membrane. Concentrations of PTX in the tumor tissue, tissue of various organs and serum, as well as the membrane, were determined 26 days after insertion of $1,200 \mu \mathrm{g}$ of PTX-containing membranes into the tumor models $(n=11)$, according to the modified high-performance liquid chromatography (HPLC) method reported by Lee et al (15). The HPLC system consisted of a Waters 1515 isocratic HPLC pump, Waters 717 plus auto sampler, Waters 2487 Dual $\lambda$ absorbance detector (Waters Corporation, Milford, MA, USA) and a computing integrator. The ultraviolet detector was set at $227 \mathrm{~nm}$. The stationary phase was a symmetry C18 column (4.6x150 mm, $5 \mu \mathrm{m}$; Waters Corporation) and the mobile phase was a ratio of acetonitrile: $99.9 \%$ methanol: $0.05 \mathrm{mM}$ phosphate buffered saline $(\mathrm{pH} 4.0)(45: 10: 45, \mathrm{v} / \mathrm{v} / \mathrm{v})$. The retention time at a flow rate of $1 \mathrm{ml} / \mathrm{min}$ was $12.1 \mathrm{~min}$ for PTX.

Statistical analysis. Data are presented as mean \pm standard error of the mean (SEM). Statistical analysis was performed 


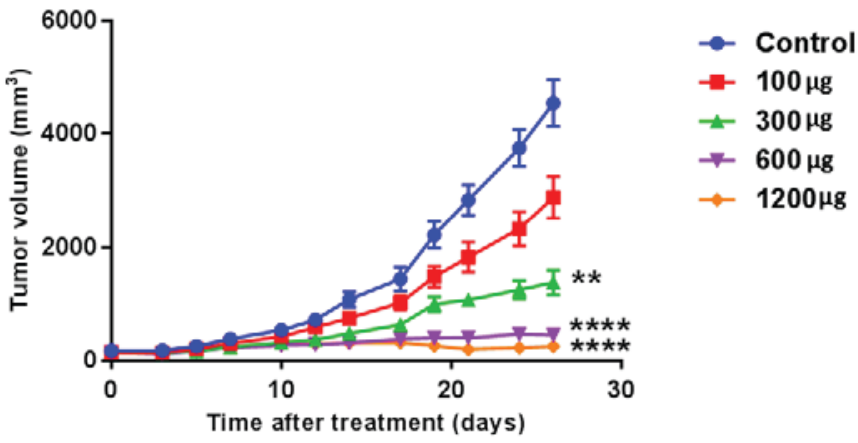

Figure 1. Alterations of tumor volume as a function of time with various amounts of PTX per disc of the membrane. Membranes containing various amounts of PTX were inserted into the subcutaneous layer beneath the tumor mass of CT26 tumor-bearing mice. Tumor size was evaluated repeatedly until 26 days after insertion of the membrane. Tumor growth was suppressed by a PTX-eluting membrane in a dose-dependent manner. Data are presented as the mean \pm SEM $(n=10) .{ }^{* *} \mathrm{P}<0.01$ and **** $\mathrm{P}<0.0001$ vs. control group.

using Friedman test (for tumor volume and body weight change) or Kruskal-Wallis test (for apoptotic cell counts) at 5\% significance level combined with Dunn's multiple comparison tests provided by GraphPad Prism 6 software (GraphPad Software, Inc., La Jolla, CA, USA). ${ }^{*} \mathrm{P}<0.05$, was considered to indicate a statistically significant difference.

\section{Results}

Antitumor activity of the PTX-eluting membrane. On day 26 after membrane treatment, tumor volumes were 4,536 $\pm 1,307$, $2,877 \pm 1,157,1,372 \pm 703,449 \pm 349$ and $252 \pm 325 \mathrm{~mm}^{3}$ when harvested in the $0,100,300,600$, and 1,200 $\mu$ g-groups, respectively ( $\mathrm{n}=10$ per group; $\mathrm{P}<0.001$; Fig. 1 ). Tumor growth was suppressed by a PTX-eluting membrane in a dose-dependent manner. Tumors of the control group revealed slow enlargement until day 12, and growth was accelerated following that time. Tumor growth of the 100 and $300 \mu$ g-groups was inhibited, and tumors of the 600 and 1,200 $\mu$ g-groups demonstrated a small level of growth from day 12 during the observation period.

Toxicity of the PTX-eluting membrane. Body weight changes between membrane insertion and harvesting revealed increases of $4.2 \pm 1.4,3.8 \pm 1.7,3.9 \pm 1.0,2.6 \pm 1.0$ and $2.1 \pm 2.0 \mathrm{~g}$ in the $0,100,300,600$, and $1,200 \mu$ g-groups, respectively, with no significant difference between the groups $(n=10$ per group; $\mathrm{P}=0.623$; Fig. 2).

Effects of PTX-eluting membranes on apoptosis. Results from the TUNEL assay demonstrated a dose-dependent increase in apoptotic cells (Fig. 3). Apoptotic cell counts per high power field (magnification, $\mathrm{x} 400$ ) on TUNEL staining of tumor tissues were $6.0 \pm 5.0,20.0 \pm 26.0,45.0 \pm 38.0,87.0 \pm 34.0$ and $116.0 \pm 74.0$ in the $0,100,300,600$, and 1,200 $\mu$ g-groups, respectively ( $\mathrm{n}=10$ per group; $\mathrm{P}<0.001$; Fig. 4).

Biodistribution of PTX following treatment of the PTX-eluting membrane. In the biodistribution analysis of PTX released from the 1,200 $\mu \mathrm{g} / \mathrm{disc}$ of PTX-eluting membranes, concentrations of PTX were significantly higher in tumor tissues

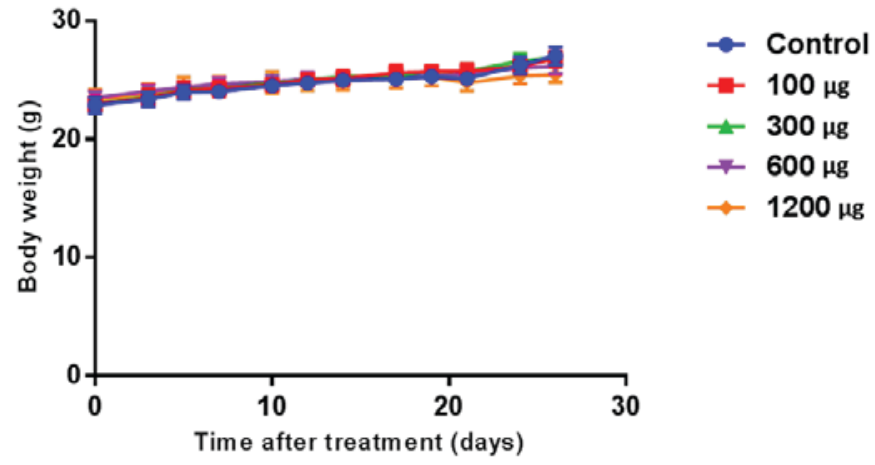

Figure 2. Alterations of body weight as a function of time after treatment with membranes containing various amounts of PTX. Body weight of the tumor model was monitored until 26 days after insertion of the membrane. Body weight changes between membrane insertion and harvesting did not differ among the groups. Data are presented as the mean \pm SEM $(n=10)$.

$(19.2 \pm 2.4 \mu \mathrm{g} / \mathrm{ml})$ on day 26 compared with those of other tissues and serum (serum, 0.9 \pm 0.2 ; liver, $0.3 \pm 0.1$; kidney, $0.7 \pm 0.1$; spleen, $2.4 \pm 0.6$; heart $4.9 \pm 1.3$; lung, $3.4 \pm 0.5 \mu \mathrm{g} / \mathrm{ml}$; $\mathrm{n}=11 ; \mathrm{P}<0.001)$. PTX was retained with a high concentration on day 26 in the membranes $(336.6 \pm 48.6 \mu \mathrm{g} / \mathrm{ml}$; Fig. 5).

\section{Discussion}

Bile duct cancer tends to grow locally without distant metastasis, and uncontrolled cholestasis and/or cholangitis caused by tumor mass obstruction of bile flow. These are important determinants of patient survival in cases of inoperable cancer. Mortality is usually caused by loco-regional disease rather than distant metastasis $(16,17)$; thus, local control of the tumor is important in prolonging the survival time of patients. Therefore, local treatment may be an effective option for palliative treatment in the unresectable stage of bile duct carcinoma.

Systemic chemotherapy has been ineffective against hypovascular bile duct carcinoma (18-21), meaning that an effective amount of anticancer agent was not able to reach the target lesion. There have been a number of efforts to increase the drug amount in cancer tissues to achieve the antitumor effect, including additional radiation treatment (22-24). However, an effective method to increase the amount of drug has not yet been developed.

Previously, through in vitro and in vivo studies, certain studies have demonstrated the possibility of topical application of anticancer drugs for unresectable cholangiocarcinoma $(1,2,4)$. Inhibition of growth of the cell line by local and controlled-release of carboplatin, PTX or OK-432 was revealed in these studies $(1,2,4)$. Furthermore, a patient with a malignant biliary obstruction effectively treated by local injection of the bioactive drug using endoscopy for palliation has previously been reported (3). These studies lead to development of a drug-eluting stent for local treatment of bile duct cancer. The PTX-eluting biliary stent was then developed and evaluated for its tissue compatibility on the normal bile duct of an animal model, which documented its safety in a living body $(5,6)$. The theoretical basis for antitumor effect of PTX in a stent is similar with local application of antitumor agent, which is maximizing its concentration within the bile duct while minimizing the systemic side effects of the agent. According to the present study, the hypothesis may be supported by the current results 


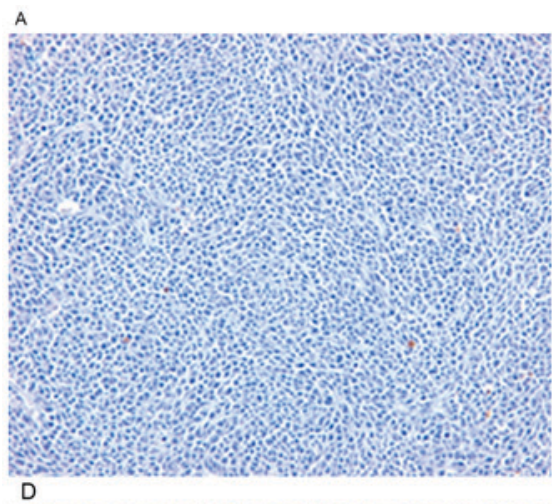

C
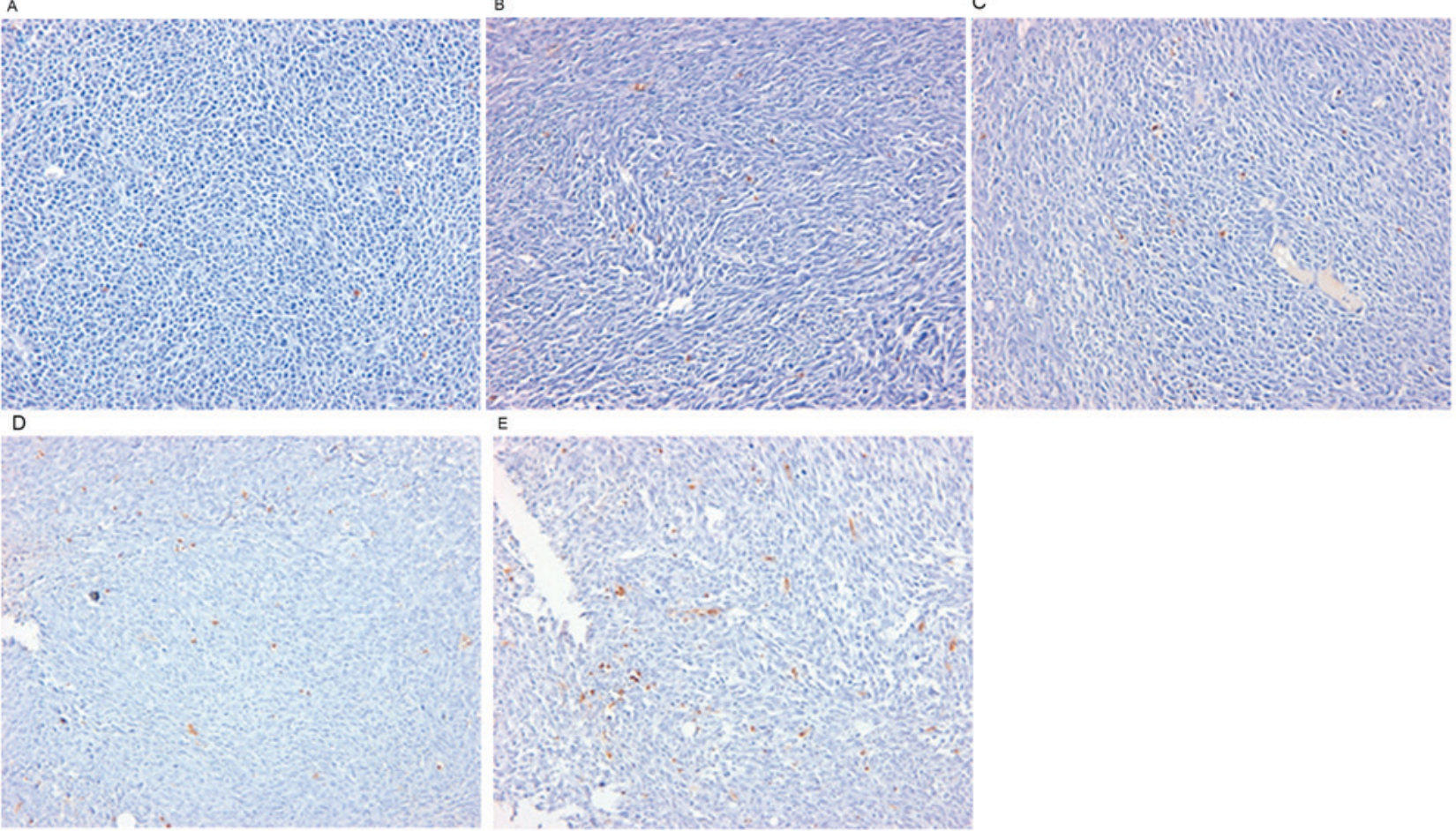

Figure 3. Results of terminal deoxynucleotidyl-transferase-mediated dUTP nick end labeling staining (magnification, $\mathrm{x} 400$ ) of harvested tumor tissues, according to the amount of paclitaxel in the membrane: (A) 0; (B) 100; (C) 300; (D) 600; and (E) 1,200 $\mu \mathrm{g} / \mathrm{disc}$. Brown-colored cells were considered apoptotic cells. Apoptotic cell count increased as the dosage of paclitaxel in the membrane increased.

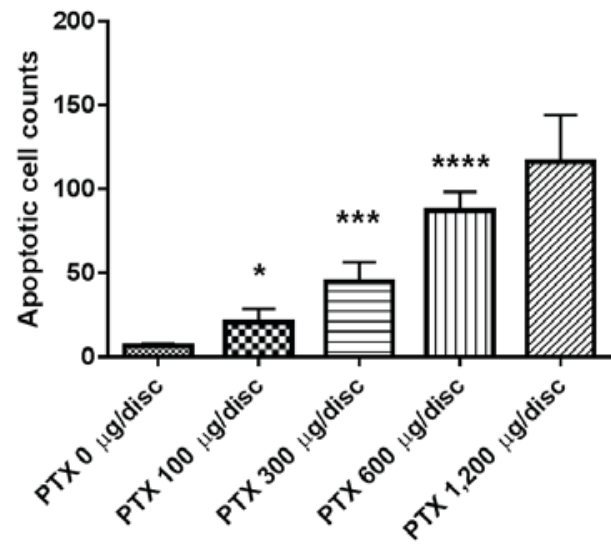

Figure 4. Apoptotic cell count per HPF (magnification, x400) with TUNEL staining of harvested tumor tissues. Following TUNEL staining, brown-colored cells were considered apoptotic cells. Cells were counted on 5 high power fields (magnification, $\mathrm{x} 400$ ) by light microscopic examination. Results of the TUNEL assay revealed a dose-dependent increase of apoptotic cells. Data are presented as the mean \pm SEM $(n=10)$. " $P<0.05$, ${ }^{* * *} \mathrm{P}<0.001$ and ${ }^{* * * * *} \mathrm{P}<0.0001$ vs. PTX $0 \mu \mathrm{g} /$ disc-group. TUNEL, terminal deoxynucleotidyl-transferase-mediated dUTP nick end labeling; HPF, high power field; PTX, paclitaxel.

that demonstrated that the higher dose of PTX in the stent revealed a more potent antitumor effect judged by suppression of tumor growth in a dose-dependent manner (Fig. 1), and the concentration of PTX was significantly higher compared with in other tissues and serum.

Preliminary clinical data on a PTX-eluting stent has been reported in patients with malignant biliary tract obstruction (7). The duration of patient survival and stent patency (350 and 429 days) were revealed to be longer for the PTX-eluting stent

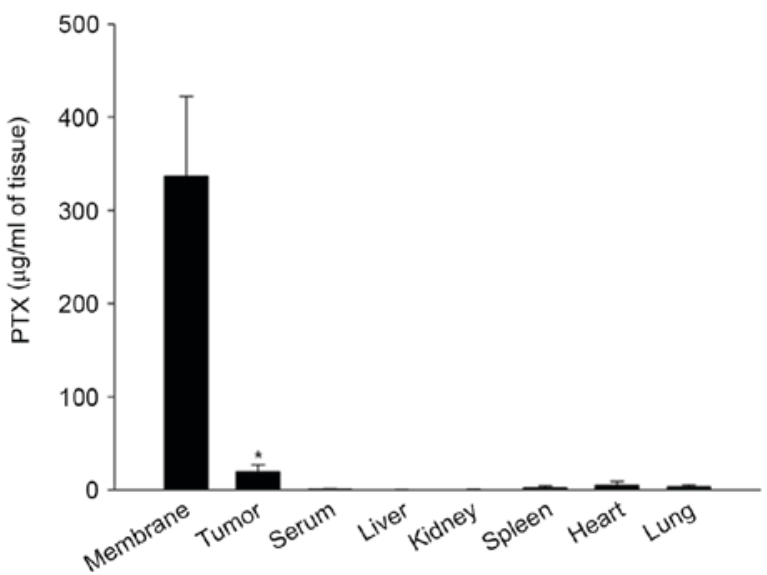

Figure 5. Biodistribution of paclitaxel eluted from polyurethane membranes. Concentrations of PTX in tumor tissues, tissues of various organs and serum, as well as the membranes, were determined 26 days after insertion of membranes containing 1,200 $\mu \mathrm{g}$ PTX into tumor models using the modified high-performance liquid chromatography method. Concentrations of PTX were significantly higher in tumor tissues on day 26 compared with those of other tissues and serum. Data are presented as the mean \pm standard error of the mean $(n=11) .{ }^{*} \mathrm{P}<0.001$ vs. the other corresponding tissues. PTX, paclitaxel.

compared with those reported for conventional covered metal stents. Thus, the results of this pilot human study suggested the possibility of the PTX-eluting stent as a local anticancer treatment option for malignant biliary obstruction (7).

The present study developed a PTX-eluting polyurethane membrane as a covering material for a biliary metal stent, designed for local and controlled release of PTX (13), which is may be more suitable for local anticancer treatment compared with systemic treatment (11). In our previous study investigating 
the drug-release profile from this membrane, an initial burst of PTX was released for the first 4 days for all different volume percentages of the PTX-eluting membranes (13). Subsequently, the gradient of the cumulative released-amount of PTX with time was gentle and constant for $>4$ weeks. These results implied that PTX is released slowly and regularly from the polyurethane membrane for $>1$ month without reference to the volume percentage. Therefore, the observation period of the tumor growth curve of the present study was established in the animal study on the basis of these results.

The slope of the tumor volume curve increased in a time-dependent manner following inoculation of cancer cells in the control group, indicating that tumor growth in the control group accelerated with time. However, other results demonstrated that tumor growth was constantly and significantly inhibited for $\geq 4$ weeks when the amount of PTX in the membrane was $\geq 600 \mu \mathrm{g}$ in the tumor volume curve of the mice. Furthermore, the antitumor activity was dose-dependent.

The present study analyzed body weight changes of the models with time for evaluation of the systemic toxicity of the PTX-eluting membrane in the experiment. Body weights were revealed to increase slowly throughout a period of 26 days in all groups. There was no significant difference in body weight alterations between the control and treatment groups. Therefore, the PTX-eluting membrane is not likely to cause any systemic toxicity.

Cancer cell apoptosis is known to be one of the main antitumor mechanisms of PTX. Results of the TUNEL assay demonstrated that the degree of cancer cell apoptosis appeared to be significantly higher in treatment groups compared with in the control group $(\mathrm{P}<0.001)$. In addition, the number of apoptotic cells increased in a dose-dependent manner among treatment groups. These results revealed that apoptosis of cancer cells is affected by the amount of PTX in PTX-eluting membranes.

In the biodistribution analysis of PTX released from the drug-delivery system in the 1,200 $\mu$ g-group, the concentration of PTX was low in the blood and peripheral tissues of various organs on day 26 after membrane insertion, whereas it was higher in tumor tissues, and the membranes. These results demonstrated that delivery of PTX from the membrane was controlled for $>4$ weeks, and the antitumor effect of this drug-delivery system did not result from the systemic effect of PTX, but was a local effect.

The results of present study demonstrated the antitumor effect of PTX membrane objectively by revealing the inhibition of tumor cell growth and apoptosis of tumor cells. In addition, the results also demonstrated that the antitumor activity of PTX in the membrane was dose-dependent. Furthermore, the present study evaluated the potential side effect of the PTX eluting membrane by assessing the biodistribution of PTX in tumor a model and weight changes of the mice. Prior to clinical application, further animal studies are required to prevent the errors in clinical application of novel medical devices in humans. The present study estimated that these results would be the cornerstones of clinical application of PTX-eluting membrane stents in patients with malignant biliary stricture.

The main limitation of the present study was that a colon adenocarcinoma cell line was selected that was syngeneic to murine rather than human cholangiocarcinoma cell lines, in which response to PTX and biological behavior may differ. The present study could not establish the cholangiocarcinoma model because an appropriate cholangiocarcinoma cell line could not be obtained. Therefore, for future clinical applications, long-term antitumor activity and safety of the PTX-eluting membrane should be documented using a cholangiocarcinoma xenograft model.

In summary, the PTX-eluting membrane demonstrated a significant, dose-dependent antitumor effect. No local or systemic toxicity was observed in all groups inserted with membranes containing various amounts of PTX. These results appeared to occur by a local effect of this system, and the system may be safe, at least within the range of the amount of PTX per membrane. Therefore, the PTX-releasing membrane may be applied in the future for development of the drug-eluting stent for local therapy of bile duct cancer. However, further studies are required in order to confirm whether the PTX-delivery system has significant antitumor activity in a human cholangiocarcinoma xenograft model, and to elucidate the mechanisms underlying a local antitumor effect of this system prior to advancement of clinical applications.

\section{Acknowledgements}

Not applicable.

\section{Funding}

The present study was supported by Inha University Hospital Research Grant.

\section{Availability of data and materials}

The datasets used and/or analyzed during the current study are available from the corresponding author on reasonable request.

\section{Authors' contributions}

JSP was responsible for study conception and design, collection and assembly of data, analysis and interpretation of data, drafting of the article, provision of study materials, and administrative and technical or logistic support. SJ was responsible for study conception and design, provision of study materials, critical revision of the article for important intellectual content and final approval of the article. DHL and JHM were responsible for administrative and technical support of the animal experiments. DHL made substantial contributions to the conception and design of the work. JHM made substantial contributions to the acquisition of data and analysis for the work. ISP made substantial contributions to the design of the work and final approval of the version to be published. SP made substantial contributions to the acquisition of data for the work and drafting it critically for important intellectual content.

\section{Ethics approval and consent to participate}

Ethical approval for the experiments with mice was obtained from the Ethics Committee of Inha University School of Medicine (approval no. INHA 130816-226). 


\section{Consent for publication}

Not applicable.

\section{Competing interests}

All authors state that there are no conflicts of interest in this study.

\section{References}

1. Mezawa S, Homma H, Sato T, Doi T, Miyanishi K, Takada K, Kukitsu T, Murase K, Yoshizaki N, Takahashi M, et al: A study of carboplatin-coated tube for the unresectable cholangiocarcinoma. Hepatology 32: 916-923, 2000.

2. Kalinowski M, Alfke H, Kleb B, Dürfeld F and Joachim Wagner H: Paclitaxel inhibits proliferation of cell lines responsible for metal stent obstruction: Possible topical application in malignant bile duct obstructions. Invest Radiol 37: 399-404 2002 .

3. Park SW, Lee DH, Park YS, Chung JB, Kang JK and Song SY: Percutaneous transhepatic choledochoscopic injection of ethanol with OK-432 mixture for palliation of malignant biliary obstruction. Gastrointest Endosc 57: 769-773, 2003.

4. Lee DH, Kang SG, Jeong S, Yoon CJ, Choi JA, Byun JN, Park JH and Lee KB: Local delivery system of immune modulating drug for unresectable adenocarcinoma: In vitro experimental study and in vivo animal study. Cardiovasc Intervent Radiol 29: 832-837, 2006.

5. Lee DK, Kim HS, Kim KS, Lee WJ, Kim HK, Won YH, Byun YR, Kim MY, Baik SK and Kwon SO: The effect on porcine bile duct of a metallic stent covered with a paclitaxel-incorporated membrane. Gastrointest Endosc 61: 296-301, 2005.

6. Lee SS, Shin JH, Han JM, Cho CH, Kim MH, Lee SK, Kim JH, Kim KR, Shin KM, Won YH and Song HY: Histologic influence of paclitaxel-eluting covered metallic stents in a canine biliary model. Gastrointest Endosc 69: 1140-1147, 2009

7. Suk KT, Kim JW, Kim HS, Baik SK, Oh SJ, Lee SJ, Kim HG, Lee DH, Won YH and Lee DK: Human application of a metallic stent covered with a paclitaxel-incorporated membrane for malignant biliary obstruction: Multicenter pilot study. Gastrointest Endosc 66: 798-803, 2007.

8. Mekhail TM and Markman M: Paclitaxel in cancer therapy. Expert Opin Pharmacother 3: 755-766, 2002.

9. Markman M, Rowinsky E, Hakes T, Reichman B, Jones W, Lewis JL Jr, Rubin S, Curtin J, Barakat R, Phillips M, et al: Phase I trial of intraperitoneal taxol: A gynecoloic oncology group study. J Clin Oncol 10: 1485-1491, 1992.
10. Burt HM, Jackson JK, Bains SK, Liggins RT, Oktaba AM, Arsenault AL and Hunter WL: Controlled delivery of taxol from microspheres composed of a blend of ethylene-vinyl acetate copolymer and poly (d,1-lactic acid). Cancer Lett 88: 73-79, 1995.

11. Dhanikula AB and Panchagnula R: Localized paclitaxel delivery. Int J Pharm 183: 85-100, 1999.

12. Pawar R, Shikanov A, Vaisman B and Domb AJ: Intravenous and regional paclitaxel formulations. Curr Med Chem 11: 397-402, 2004.

13. Kang SG, Lee SC, Choi SH, Park S, Jeong S, Lee HD and Kim M: Paclitaxel-polyurethane film for anti-cancer drug delivery: Film characterization and preliminary in vivo study. Macromol Res 18: 680-685, 2010.

14. Uchiyama-Kokubu $\mathrm{N}$ and Watanabe T: Establishment and characterization of adriamycin-resistant human colorectal adenocarcinoma HCT-15 cell lines with multidrug resistance. Anticancer Drugs 12: 769-779, 2001.

15. Lee SH, Yoo SD and Lee KH: Rapid and sensitive determination of paclitaxel in mouse plasma by high-performance liquid chromatography. J Chromatogr B Biomed Sci Appl 724: 357-363, 1999.

16. Mittal B, Deutsch M and Iwatsuki S: Primary cancers of extrahepatic biliary passages. Int J Radiat Oncol Biol Phys 11: 849-854, 1985.

17. Klatskin G: Adenocarcinoma of the hepatic duct at its bifurcation within the porta hepatis. an unusual tumor with distinctive clinical and pathological features. Am J Med 38: 241-256, 1965.

18. Harvey JH, Smith FP and Schein PS: 5-fluorouracil, mitomycin, and doxorubicin (FAM) in carcinoma of the biliary tract. J Clin Oncol 2: 1245-1248, 1984.

19. Falkson G, MacIntyre JM and Moertel CG: Eastern cooperative oncology group experience with chemotherapy for inoperable gallbladder and bile duct cancer. Cancer 54: 965-969, 1984.

20. Altaee MY, Johnson PJ, Farrant JM and Williams R: Etiologic and clinical characteristics of peripheral and hilar cholangiocarcinoma. Cancer 68: 2051-2055, 1991.

21. Jones DV Jr, Lozano R, Hoque A, Markowitz A and Patt YZ: Phase II study of paclitaxel therapy for unresectable biliary tree carcinomas. J Clin Oncol 14: 2306-2310, 1996.

22. Buskirk SJ, Gunderson LL, Adson MA, Martinez A, May GR, McIlrath DC, Nagorney DM, Edmundson GK, Bender CE and Martin JK Jr: Analysis of failure following curative irradiation of gallbladder and extrahepatic bile duct carcinoma. Int J Radiat Oncol Biol Phys 10: 2013-2023, 1984.

23. Flickinger JC, Epstein AH, Iwatsuki S, Carr BI and Starzl TE: Radiation therapy for primary carcinoma of the extrahepatic biliary system. An analysis of 63 cases. Cancer 68: 289-294, 1991.

24. Tsujino K, Landry JC, Smith RG, Keller JW, Williams WH and Davis LW: Definitive radiation therapy for extrahepatic bile duct carcinoma. Radiology 196: 275-280, 1995. 